\title{
A RAPID VOLUMETRIC METHOD FOR THE ESTIMATION OF IRON. APPLICABLE IN THE PRESENCE OF HYDROCHLORIC ACID, PHOSPHORUS, OXY-ACIDS, AND ORGANIC MATTER.
}

By H. DROOP RICHMOND, F.I.C., AND EDITH M. ISON, B.So., A.I.C.

(Read at the Meeting, May 5, 1920.)

Owise to the presence of sugar, phosphorus compounds, and other compounds in syrups, the conventional methods of iron determination are not applicable, and as much of the therapeutic effect of the syrups is due to the iron present, it is highly desirable to be able to estimate its amount rapidly and with accuracy.

The method we describe, which is both rapid and accurate, depends on the following facts :

1. In $5 N$ hydrochloric acid solution iron is completely ionised, even if phosphates and organic maitter be present. 


\section{A RAPID VOLUMETRIC METHOD FOR THE ESTIMATION OF IRON 259}

2. Permanganates oxidise ferrous ions to ferric ions in the presence of sugars, and also destroy the colouring matters used in the syrups. In oxidising ferrous to ferric ions by standard permanganate, the amount used before the colour is discharged shows that oxidation of the ferrous ion takes preference over that of the dye, while the sugar is attacked in a still less degree.

3. A small excess of permanganate is reduced completely by the sugars, and practically no chlorine is liberated.

4. Ferricyanides are sensitive indicators for the production of ferrous ions, and thiocyanates for their removal.

5. Stannous chloride reduces ferric to ferrous ions, and in an atmosphere of carbon dioxide the reduction is a measure of the iron present.

We operate thus : 5 or 10 c.c. of the syrup is measured (or weighed) into a 100 c.c. flask, a fow drops of strong hydrochloric acid added, and $\frac{N}{10}$ permanganate solution run in till a transitory purple is produced throughout the solution, the colour of such syrups as Syrupus ferri phosphatis compositus or Syrupus ferri glycerophosphatis compositus being destroyed during the addition of the permanganate. The purple colour vanishes rapidly, and usually the solution contains no free chlorine, and the iron present is entirely in the ferric state. An equal bulk of strong hydrochloric acid is added, and a little sodium bicarbonate dropped in to give an atmosphere of carbon dioxide in the flask; 1 drop of $\frac{N}{10}$ stannous chloride solution is added, and a drop of the mixture added to a drop of a freshly prepared ferricyanide solution on a white tile; a blue coloration generally results, except in cases where a great excess of permanganate was added, and in these cases stannous chloride must be added till a reaction for ferrous iron is given. The solution, which has the usual bright yellow colour of ferric salts in strong hydrochloric acid, is now titrated till the colour becomes faint, and the titration continued till a drop no longer colours a drop of a solution of a thiocyanate on a white tile. The number of c.c. used multiplied by 0.0056 will give the weight of iron present.

With careful oxidation the use of the ferricyanide indicator may be dispensed with, and with non-coloured solutions the disappearance of the yellow marks the end point.

The results below show the accuracy of the method :

Iron solution containing by gravimetric analysis 0.837 grm. Fe per 100 c.c.; aqueous solution, 0.833 ; after re-oxidising, 0.832 ; sugar solution, 0.835 .

Syrupus ferri phosphatis, B.P. theory, 0.87 per cent. (three samples) : 0.835 and $0.825,0.86,0.868$.

Syrupus ferri phosphatis compositus theory, 0.437 per cent. : 0.437 and 0.422 .

Another sample +5 per cent. extra iron, theory 0.46 per cent. : 0.46 .

Syrupus ferri phosphatis compositus, another sample strong in iron: 0.482 and 0.485 .

Syrupus ferri glycerophosphatis compositus, B.P.C. theory : 0.087 per cent. (two samples): 0.088 and $0.087,0.084$.

Syrupus ferri hypophosphatis, made to contain 0.48 per cent.: $0.46,0.49$, and 0.48 .

Easton's syrup theory, 0.87 (three samples) : $0.835,0.88,0.85$. 
Ferri phosphas saccharatus (one of strength below B.P. requirements, one of B.P. strength) : $51 \cdot 8,64 \cdot 1$; Romijn's method, 51·4, $64 \cdot 6$.

Syrupus glycerophosphatis cum formatibus, B.P.C. theory, 0.087 per cent. (known to be low) : $0.069,0.067$; after oxidation, 0.066 .

Glycerinum glycerophosphatum compositum, B.P.C. theory: 0.081, 0.087.

We find that if the stannous chloride solution be kept in an atmosphere of hydrogen, it loses strength at so slow a rate that occasional checking of its titre only is required. In the absence of organic matter this method may be combined with a permanganate titration in hydrochloric acid solution thus: the iron having been brought to the ferrous state by any of the usual methods, the solution is titrated with $\frac{N}{10}$ permanganate; half the volume of strong hydrochloric acid is added, and the solution titrated back with $\frac{N}{10}$ stannous chloride, using ferricyanide as indicator, and the amount used subtracted from the permanganate titration, and the remainder gives an estimation of the iron. The titration with stannous chloride may be continued to the thiocyanate end point, and gives another iron estimation which agrees closely with the corrected permanganate figure.

This work was carried out in the analytical laboratory of Boots' Pure Drug Company, Ltd., to whom our thanks are due. 